Os saberes para ensinar matemática e a profissionalização do educador matemático

\author{
The knowledge to teach mathematics and \\ the professionalization of mathematics educator
}

\title{
Wagner Rodrigues Valente*
}

Universidade Federal de São Paulo, Campus Guarulhos, SP, Brasil

\section{Resumo}

Este texto analisa os saberes na formação de professores. Em específico, da formação matemática tanto para os futuros docentes do Ensino Fundamental como para aqueles do Ensino Médio, considerando a terminologia atual do sistema escolar brasileiro. Na análise, o texto apoia-se nos estudos que vem sendo desenvolvidos pela Equipe de Pesquisa em História das Ciências da Educação (ERHISE) da Universidade de Genebra, na Suíça. Buscar-se-á mostrar que a profissionalização do educador matemático, em contraposição ao professor de matemática, tem na "matemática para ensinar" sua referência constitutiva. A base empírica do estudo leva em consideração pesquisas relacionadas à história da educação matemática brasileira, em especial, a década de 1930, em que teve destaque as ações do professor Euclides Roxo.

*WRV: Pós-doutorado em Educação, e-mail: ghemat.contato@gmail.com 
Palavras-chave: Saber a ensinar. Saber para ensinar. Euclides Roxo. Educação matemática.

\begin{abstract}
This paper analyzes the role of knowledge in teacher training. In particular, it deals with the mathematical training both future teachers of Ensino Fundamental (elementary school) as those of Ensino Médio (high school), considering the current terminology of the Brazilian school system. In the analysis, the text builds on studies that have been developed by the Research Team in the History of Educational Sciences (ERHISE), University of Geneva, Switzerland. Search It will show that the professionalization of mathematics educator, in contrast to the math teacher, has the "math to teach" its constitutive reference. The empirical basis of the study takes into account research related to the history of Brazilian mathematics education, especially the 1930s, which had highlighted the actions of Euclides Roxo teacher.
\end{abstract}

Keywords: Knowledge to teach. Knowledge for teaching. Euclides Roxo. Mathematics education.

\title{
Resumen
}

Este trabajo analiza el papel del conocimiento en la formación del profesorado. En particular, se trata de la formación matemática tanto a los futuros maestros de la escuela primaria como los de la escuela secundaria. En el análisis, el texto se basa en estudios que han sido desarrollados por el Equipo de Investigación en Historia de la Ciencias de la Educación (ERHISE), Universidad de Ginebra, Suiza. Mostrará que la profesionalización del educador matemático, en contraste con el profesor de matemáticas, tiene la "matemáticas para enseñar" su referencia constitutiva. La base empírica del estudio toma en cuenta la investigación relacionada con la historia de la educación matemática brasileña, especialmente la década de 1930, que se había puesto de relieve las acciones del profesor Euclides Roxo.

Palabras clave: Saber a enseñar. Saber para enseñar. Euclides Roxo. Educación matemática. 


\section{Introdução}

Por certo, já vem de longa data a discussão sobre a formação de professores. No entanto, ao que tudo indica, somente em décadas recentes tal tema problematiza, especificamente os saberes de formação do professor de matemática. Há uma única matemática a constituir essa formação? Ou para licenciandos, para bacharéis e matemáticos deve ser considerado que há diferentes matemáticas? No âmbito da Educação Matemática, ao que parece, as pesquisas consideram a existência de diferentes matemáticas ${ }^{1}$. Porém, mesmo advogando a existência de diferentes matemáticas, permanece uma essência, um saber matemático único que sofrerá diferentes atribuições de significado a depender do usuário ao qual é destinado esse saber. A distinção não é, portanto, em termos da objetivação de diferentes saberes matemáticos, em termos epistemológicos. $\mathrm{E}$, neste caso, tudo indica que se estabelece uma hierarquia: a matemática dos matemáticos e as demais, a depender do uso que é feito dessa matemática dos matemáticos...

Este texto tem por objetivo enfatizar os saberes matemáticos que formam o professor de matemática, em termos da constituição de um novo profissional: o educador matemático. E, neste caso, considera que no processo histórico constituem-se saberes matemáticos de diferentes naturezas, evidenciando status epistemológicos próprios. Para tal propósito, este estudo lança mão de sistematizações teóricas do Grupo ERHISE2. Será por meio da caracterização dos "saberes a ensinar" e dos "saberes para ensinar" que, por hipótese de trabalho, melhor poderia ser caracterizada essa nova profissão docente: a do educador matemático. Desse modo, cabe a interrogação: como se constituem a "matemática a ensinar" e a "matemática para ensinar"? Discutida essa caracterização de saberes, buscar-se-á mostrar que a profissionalização do educador matemático tem na "matemática para ensinar" sua referência constitutiva.

1 Leiam-se, por exemplo, os estudos de Moreira; David (2005) e Santos; Lins (2016).

2 Para maiores informações sobre esse grupo de pesquisa veja-se: $h$ ttps://cms.unige.ch/fapse/SSE/ erhise/ 


\section{O saber a ensinar e o saber para ensinar}

A discussão sobre a formação de professores envolve desde os primeiros tempos, em que era pensada a sua institucionalização, no curso do século XIX, os saberes específicos para a profissão de ensinar. Que saberes deveriam possuir os profissionais da docência? Análises sobre a organização desses saberes mostram proximidade dos processos de sua elaboração em diferentes países (BORER, 2009). Tais análises têm sido sistematizadas pela Equipe de Pesquisa em História das Ciências da Educação (ERHISE) da Universidade de Genebra, na Suíça. O que elas revelam? Que as dinâmicas de constituição dos saberes para a formação de professores no nível primário (os primeiros anos escolares) e do nível secundário (os anos escolares compreendidos pós-ensino primário e pré-ensino universitário) ligam-se à compreensão

de como se articulam de um lado os saberes constitutivos do campo profissional, no qual a referência é a expertise profissional (saberes profissionais ou saberes para ensinar); e, de outro, os saberes emanados dos campos disciplinares de referência produzidos pelas disciplinas universitárias (saberes disciplinares ou saberes concernentes aos saberes a ensinar) (BORER, 2009, p. 42, grifo da autora, tradução nossa).

Para além disso, em termos de análise da constituição dos saberes para a profissão docente, há que se ter em conta nessas dinâmicas,

[...] as tensões em jogo nas instâncias que contribuem de diferentes maneiras para definir esses saberes considerando: a profissão de professor e as associações/sindicatos que a representam; a administração escolar (departamentos de instrução pública, serviços de ensino primário, secundário, superior); as faculdades universitárias (com as disciplinas de referência do ensino e da pedagogia/ciência(s) da educação) (BORER, 2009, p. 43, tradução nossa). 
Em termos dos saberes específicos para ensinar, os saberes para a profissão da docência, tendo em conta o nível primário, o da formação de professores primários, historicamente tem-se dois modelos: o das escolas normais e o das escolas de nível superior que formam professores para atuarem nos primeiros anos escolares.

As escolas normais oferecem uma formação tanto geral como profissional. Logo, a formação geral refere-se a um leque de disciplinas ministradas em nível secundário; já a formação profissional liga-se a uma diminuta inserção de saberes vindos das cadeiras das ciências da educação, sobretudo, a cargo do diretor escolar, uma espécie de mentor pedagógico do trabalho. No entanto, com o passar do tempo, se ampliam os cuidados com a formação profissional, surgindo rubricas específicas para isso. No caso da formação realizada no nível superior tem uma nítida separação entre os saberes de formação geral e aqueles profissionais. Considerando os saberes de formação geral, eles são ministrados no curso secundário; assim, a formação em nível superior, lançando mão das ciências da educação, e suas cadeiras disciplinares, encarrega-se dos saberes profissionais (BORER, 2009).

Do ponto de vista do que mais interessa a esta síntese - tratar da evolução dos saberes envolvidos na formação de professores - cabe verificar as diferenças de trajetória desses saberes de acordo com cada um dos modelos: normal e superior. Levando em conta a formação dada pelas escolas normais ao longo do tempo, ampliando os estudos, o número de anos de formação, com domínio dos saberes de formação geral dada pelas disciplinas escolares, mesmo que, com o passar dos anos tenha-se uma inserção progressiva dos saberes profissionais, dos saberes para ensinar.

A análise da formação de professores para os primeiros anos escolares, realizada no nível superior, mostra que os saberes para o exercício docente se afirmam a partir de uma base de formação de cultura geral dada nos estudos secundários, sendo a formação profissional dada pelos estudos pedagógicos. Neles estão presentes os saberes para ensinar, sobretudo nos ensinos de pedagogia teórica e prática, psicologia, ciências da educação, aos quais se ligam também as didáticas e metodologias das diferentes disciplinas escolares. 
Como resultado dessa análise constata-se que

[...] o modelo superior é mais favorável ao desenvolvimento de saberes para ensinar no seio das formações para o ensino; o modelo normal se encontra sob tensão entre a missão de assegurar a melhor formação geral possível e sua vocação profissional. E essa tensão, que se nota cada vez mais ao longo do tempo, com o aumento das exigências relativas ao nível de instrução dos professores do primário, leva regularmente as escolas normais ainda mais para uma formação geral em detrimento da formação profissional (BORER, 2009, p. 45 grifos da autora, tradução nossa).

No que toca o ensino secundário observa-se, praticamente, a inexistência de uma formação profissional para esse nível de ensino até o final do século XIX. No entanto,

desde o início do século XX, os departamentos de instrução pública, as associações de professores e mesmo as congregações religiosas reivindicam a inclusão de saberes para ensinar e de experiências práticas para aperfeiçoar as qualificações dos professores do secundário. Aulas metodológicas/didáticas específicas e, em seguida os exercícios práticos são organizados no quadro dos certificados de aptidão ao ensino secundário que são pouco a pouco criados em todas as faculdades das universidades [...] (BORER, 2009, p. 45, tradução nossa).

Ao contrário do que se possa imaginar, essas iniciativas de aperfeiçoamento profissional vindas da inclusão de saberes para ensinar, no seio da formação de professores para o ensino secundário, não têm uma rota de continuidade, sobretudo, pela autonomia das universidades, que se embatem com demandas de entidades a ela externas (secretarias de educação, associações de professores etc.) e ainda, pelas cadeiras disciplinares universitárias "que contestam a legitimidade dos professores de pedagogia em relação à didática das disciplinas” (BORER, 2009, p. 46, tradução nossa), arrogando para si a produção dos saberes didáticos das disciplinas às quais se vinculam. 
Nesse contexto, se instala uma outra lógica para a formação de professores para o nível secundário de ensino. Ela legitima a competência aos professores das disciplinas, dos docentes responsáveis pelos saberes a ensinar, como base da formação docente. A outras instâncias caberiam as discussões de caráter pedagógico, dadas por faculdades de educação, ou mesmo por cursos de formação continuada sob a responsabilidade de secretarias governamentais do ensino. De todo modo, as ciências da educação afastam-se do núcleo formativo docente e o caráter de sólida formação é atribuído aos saberes a ensinar, vindo do campo disciplinar de cada especificidade científica. Tem-se, desse modo que:

[...] os saberes de referência sob os quais se fundam a profissão e a identidade profissional dos professores do ensino secundário são, antes de tudo, constituídos por saberes disciplinares ligados aos saberes a ensinar. Esta referência predominante aos saberes disciplinares coloca um problema para a profissão do secundário, pois à medida que os saberes se diferenciam, as identidades profissionais dos professores do secundário se reforçam mais em relação aos saberes a ensinar na sua disciplina do que em relação aos saberes para ensinar que os reuniriam em torno de uma profissão comum de professor do secundário (BORER, 2009, p. 49, tradução nossa).

Como resultado dessa evolução observa-se que:

O processo de profissionalização dos professores do secundário é, assim, caracterizado pelo fato de se basear em saberes dos quais a profissão participa apenas de modo limitado: os saberes disciplinares são desenvolvidos pela universidade especialmente pelas faculdades de letras, ciências e ciências sociais; os saberes profissionais aparecem como órfãos de disciplinas de referência teoricamente construídas e totalmente reconhecidas pela profissão (BORER, 2009, p. 51, tradução nossa).

Ao que parece, será essa orfandade um dos determinantes da criação das disciplinas escolares (CHERVEL, 1990) no nível secundário. Ao longo do tempo, as disciplinas acadêmico-científicas de referência 
existentes no seio das universidades, base da formação de professores de ciências, de matemática etc., se afastam cada vez mais dos saberes a ensinar na escola secundária, eles se especializam cada vez mais. Esse processo é acompanhado pela criação de saberes a ensinar que mantêm uma autonomia relativa das disciplinas ministradas no curso de formação dado nas universidades.

Esta evolução leva a especialização progressiva da didática geral em didáticas especiais ligadas às diferentes disciplinas. Essa perspectiva está cada vez mais presente no âmbito da formação de professores, na intersecção dos saberes disciplinares, com os saberes para ensinar e com os saberes a ensinar (BORER, 2009, p. 53, tradução nossa).

Em síntese, a formação de professores de níveis primário e secundário, referente aos saberes de sua formação, difere pelas referências colocadas historicamente. Parte dos professores em formação para o curso primário garante, no núcleo formativo para a profissão, a presença dos saberes para ensinar, elaboração onde vivamente participam as ciências da educação. No que diz respeito aos saberes para a formação dos professores do curso secundário, os saberes para ensinar emergem do próprio âmbito do saber a ensinar.

\section{A matemática: saber a ensinar, saber para ensinar}

Vê-se que sistematização acima caracteriza os saberes profissionais docentes, considerando-os como tendo duas naturezas: o saber a ensinar, que mantém vínculo com as disciplinas universitárias científicas, com campos específicos do saber produzido fora da escola e constituem objeto de trabalho do professor; e o saber para ensinar, fruto de elaboração histórica do ofício docente, ferramental acionado para melhor realizar o ofício de ensinar os saberes que a sociedade atribui à escola como sua função institucional. 
Diante dessa elaboração teórica, que melhor possibilita compreender a especificidade profissional docente, cabe a interrogação sobre os saberes matemáticos, tema deste artigo. Como caracterizar a "matemática a ensinar" e a "matemática para ensinar"?

Os estudos de Hofstetter; Schneuwly (2009) permitem-nos avaliar como pouco problemática a caracterização do "saber a ensinar". Assentada nas referências disciplinares, a formação do professor de matemática tem nas rubricas de cunho matemático, da produção decantada ao longo do tempo por matemáticos, sistematizada e organizada em forma de disciplinas, a sua caracterização. Cálculo Diferencial e Integral, Álgebra Linear, Vetores e Geometria etc., são exemplos da "matemática a ensinar" que compõem a formação do licenciado em matemática. Da mesma forma, Matemática, Desenho, Geometria, entre outros, são referências do saber matemático presente, a depender da época histórica, na formação de docentes dos anos iniciais escolares. Constituem a "matemática a ensinar" que integra a formação do normalista, do pedagogo, do futuro profissional que irá atuar no atual Ensino Fundamental I. A história da formação de professores poderá melhor revelar o movimento de transformação dessas disciplinas, do desaparecimento de algumas delas - por exemplo, do Desenho no caso da formação de licenciados e bacharéis em matemática - do surgimento de outras disciplinas, por exemplo, todo um rol de rubricas matemáticas advindas de um tempo conhecido como estruturalismo nas ciências, na matemática, do bourbakismo, do que Patras (2001) considera "uma corrente de pensamento dominante tanto do ponto de vista epistemológico quanto da prática do fazer matemático a partir dos anos 1950", que ainda hoje deixa marcas em várias disciplinas matemáticas do currículo dos cursos de licenciatura e bacharelado em matemática. O mesmo se pode dizer com exemplos relativos à formação do professor que ensina matemática, por exemplo: o surgimento e o desaparecimento da rubrica "Sistema de pesos e medidas"; também da disciplina "Estatística para a educação" etc. Tais casos mostram, como se disse, o movimento de transformação que sofrem os saberes a ensinar, "a matemática a ensinar". 
Se a caracterização da "matemática a ensinar" parece não trazer dificuldades maiores, o mesmo não ocorre com a "matemática para ensinar". Do que trataria tal "matemática”? Haveria sentido denominá-la "matemática"? Se ela não remete aos campos disciplinares, às rubricas sistematizadas no âmbito da produção matemática colocada para a formação de professores, quais seriam as referências da "matemática para ensinar"?

Retorne-se, pois, à sistematização teórica que vem sendo elaborada pelo grupo suíço, pelo ERHISE - da Universidade de Genebra. Os saberes para ensinar levam-nos a todo um ferramental, a todos os utensílios que deverão ser mobilizados pelo futuro docente para cumprir o seu ofício de ensinar. Assim, se o "saber a ensinar" constitui o objeto de trabalho docente, o "saber para ensinar" traduz-se como um saber capaz de tomar esse objeto constituindo-o como um ensinável, um saber como instrumento de trabalho. No entanto, vale ressaltar que essa é uma perspectiva diferente daquelas que levam em consideração o saber a partir de sua mobilização no fazer pedagógico. Hofstetter e Schneuwly (2009) afirmam que, ao contrário de tomar os saberes em ação mobilizados na prática pedagógica, a caracterização dos "saberes para ensinar" envolve saberes formalizados, objetivados e passíveis de serem estudados na análise de seu papel nas profissões do ensino e da formação (p. 18).

A interrogação que poderia ser feita, tendo em vista esse alerta relativo à caracterização dos saberes que participam da formação docente (saber a ensinar, saber para ensinar), refere-se à sua objetivação/sistematização. Em particular, a pergunta caberia preferencialmente àqueles saberes considerados como "saberes para ensinar" visto que os "saberes a ensinar" sistematizam-se e são objetivados pela constituição das disciplinas científicas de referência. Como se constituem e objetivam, pois, os "saberes para ensinar"? A análise histórica responde a essa questão. Em síntese, Borer (2009) avalia que, pelos estudos já realizados pelo grupo suíço, também em âmbito comparativo há:

progressivamente a especialização de saberes inicialmente incluídos sob a denominação de "pedagogia geral", que se transformam em 
seguida em saberes psicológicos aplicados à educação e metodologias/ didáticas - os saberes didáticos se especializam, por sua vez, em função das diferentes disciplinas a ensinar. A estes saberes se misturam igualmente os aportes das ciências contributivas, como as ciências médicas, jurídicas e sociais que estão interessadas na educação e na criança e que são convidadas a participar na formação de novas profissões educativas que emergem progressivamente (pedagogia curativa, orientação profissional e escolar etc.). Assim, se desenvolve um campo pluridisciplinar das ciências da educação que experimenta um crescimento mais ou menos significativo em função das universidades, mas que se tornou incontornável ao final do período estudado, sobretudo pela sua contribuição para as diferentes profissões do ensino e da educação (p. 49).

A citação revela toda a complexidade que envolve a constituição e objetivação dos "saberes para ensinar". E esse processo, justamente, liga-se à institucionalização desses saberes. Longe de caracterizar os "saberes para ensinar" como metodologias, a análise histórica revela a multiplicidade de dimensões presentes na evolução desses saberes. Esse trato mais amplo dos "saberes para ensinar" leva-nos a retornar à especificidade da temática aqui tratada: que saberes estão envolvidos na formação docente quando tratamos da Matemática? Mais precisamente, como investigar a evolução dos "saberes para ensinar" matemática, da matemática para ensinar? De modo semelhante aos estudos do grupo ERHISE caberá realizar investigações históricas. E essas investigações referem-se aos processos, dinâmicas, apropriações e sistematizações que podem ser lidas em documentos como programas de ensino, revistas pedagógicas, livros e manuais didáticos, dentre outros. $\mathrm{O}$ estudo dessa documentação num dado período deverá buscar analisar que elementos vão sendo decantados a partir de relatos de experiências, de discursos sobre processos didático-pedagógicos, de orientações metodológicas, de orientações oficiais para o ensino etc. relativos aos conhecimentos que o futuro docente deverá ter para o ensino de uma dada rubrica matemática. A percepção de rupturas e permanências objetivadas em programas de ensino, por exemplo, 
irão revelar trajetórias de organização de saberes para ensinar matemática. Por certo, toda a formação dita pedagógica, vinda de disciplinas como Sociologia da Educação, Filosofia da Educação, Psicologia da Educação, História da Educação dentre outras mais, concorrem para a constituição dos saberes para ensinar. Mas, a objetivação da "matemática para ensinar" deverá ser investigada em nível mais específico, nas suas articulações com a "matemática a ensinar".

\section{Euclides Roxo e a objetivação de um saber para ensinar matemática}

Em meio a essa teorização, que envolve a caracterização dos saberes a ensinar e saberes para ensinar, e a necessidade de melhor explicitar o significado da "matemática para ensinar" caberia um exemplo, vindo de estudos históricos que focalizam uma época importante nas discussões sobre a matemática do curso secundário brasileiro e internacional.

Em 1908, na cidade de Roma, matemáticos manifestavam preocupação com o ensino da matemática. É a primeira vez que matemáticos reunidos em congresso internacional consideraram ser importante debater questões ligadas ao ensino. Ao que parece, de modo inédito até então, buscava-se internacionalizar o ensino da matemática. David Eugene Smith, professor de matemática do Teachers College de Nova Iorque, viu suas intenções, apresentadas em 1905, finalmente serem acatadas. Naquele ano, Smith sugeriu a criação de uma comissão internacional para estudo do ensino de matemática. A comissão foi criada, em Roma, por ocasião do IV Congresso Internacional de Matemáticos (CIEM, 1908, p. 446). Fica conhecida por CIEM/IMUK.

Constituída a comissão, para dirigi-la, foi eleito um comitê central, com a direção dos matemáticos Félix Klein, Henri Fehr e George Greenhill. Os trabalhos se colocaram em andamento. Em questão, uma reforma do ensino da matemática.

Euclides Roxo, professor de matemática do Colégio Pedro II, no Rio Janeiro, - referência do ensino secundário brasileiro em meados 
dos anos 1920 - integra a Comissão de Ensino do Colégio responsável pela programação de matemática. O matemático propôs à Congregação do Pedro II uma alteração radical no ensino de disciplina. O projeto foi elaborado a partir de vários "considerandos". Desde o primeiro, Roxo retomou a discussão internacional sobre modernização do ensino trazida pela Alemanha à CIEM/IMUK (VALENTE, 2004).

A nova proposta posta em marcha com o programa do $1^{\circ}$ ano em 1929 teve, para o ano seguinte, a adoção de um novo livro didático adotado para o ensino de matemática no Colégio Pedro II. A obra foi lançada por Euclides Roxo ainda em 1929: Curso de Matemática. Na capa do novo didático, a advertência de que o livro tinha sido elaborado de acordo com os programas atuais do Colégio Pedro II. Roxo escreve um longo Prefácio onde sintetiza sua adesão ao movimento modernizador do ensino de matemática, vindo por meio da CIEM/IMUK.

O novo livro didático de matemática teve a finalidade de objetivar a proposta de modernização do ensino no Brasil. A intenção era a reestruturação da sequência de conteúdos a ensinar, visando a fusão dos vários ramos (aritmética, álgebra, geometria), até então, separados. De fato, a proposta revela-se muito mais do que uma simples reorganização da matemática escolar do secundário, ela buscou institucionalizar, a partir do Colégio Pedro II, escola secundária modelo para todo o país, um novo saber docente, um saber para ensinar matemática. Em época de intensa segmentação e fragmentação da pesquisa matemática, da constituição cada vez mais ampla de subdisciplinas matemáticas universitárias, a proposta de romper com os ramos em separado do ensino (aritmética, álgebra e geometria) implicou na fusão deles. Isso em nada teve a ver com uma corrente de transmissão disciplinar da matemática universitária para aquela do curso secundário. A matemática universitária mais e mais se fragmentava, enquanto que aquela para o ensino secundário buscava totalidade. Tratava-se de discutir as ferramentas que o professor secundário deveria possuir para o seu ensino. E neste caso, caberia ao docente saber articular a aritmética com a geometria e a álgebra. E essa articulação produziria um saber para ensinar a matemática. Por certo, a proposta teve 
muitas reações adversas. Dentre elas, reações que buscavam preservar o sentido do espraiamento das disciplinas em nível universitário, também no curso secundário, como as do professor Sebastião Fontes, tenente coronel, professor de matemática da Escola Militar do Rio de Janeiro: “[...] no estudo da matemática, a mistura das partes diferentes em que essa ciência se dividiu, lentamente, especializando-se através dos tempos, para ministrá-los, englobadamente, aos estudantes, me parece uma volta aos tempos primitivos dessa ciência" (FONTES, 1930). Tal reação pode ser interpretada como um rechaço à autonomia de um novo saber: a "matemática para ensinar". Fontes advogou, nos termos da análise que estamos empreendendo, a "matemática a ensinar", sem reconhecer a "matemática para ensinar". Pleiteou a continuidade da ligação e referência do ensino às disciplinas universitárias matemáticas.

A nova disciplina escolar surgida com as iniciativas de Euclides Roxo, nas apropriações que fez do movimento internacional, utilizando-se de uma conjuntura política favorável - a revolução de 1930, dando-lhe todo poder e autonomia para transformar as referências do ensino de matemática no curso secundário - constituiu, àquela altura, um passo importante na trajetória de elaboração da "matemática para ensinar".

\section{Considerações finais}

É bastante comum confundir a docência em matemática com o ofício matemático. O professor de matemática visto como um matemático. Possivelmente, uma das razões pelas quais isso ocorra tenha a ver com o que se discutiu anteriormente, sobre a evolução da docência no ensino secundário: uma ligação artificial do profissional da docência na escola básica com as ciências universitárias matemáticas. Certamente a formação de professores de matemática e professores que ensinam matemática deverá incluir a "matemática a ensinar". Essa formação constrói uma ligação com a matemática disciplinar, em termos da matemática que a sociedade espera que os docentes dominem. Tal matemática é necessária, 
fundamental, mas não suficiente ao ofício da docência. Longa marcha se estabelece na construção da matemática para ensinar. Das pedagogias e didáticas gerais, passando pela psicologia, sociologia, antropologia, pouco a pouco vai sendo constituído um saber que mais diretamente caracteriza o ofício docente, que lhe confere identidade profissional. Tal saber aponta para a "matemática para ensinar". O exemplo histórico trazido a este texto evocando Euclides Roxo é significativo: os saberes atuais da docência enfatizam a necessidade da articulação dos aspectos numérico, algébrico e geométricos na aprendizagem da matemática. Decantou-se ao longo do tempo tal saber para ensinar, tal matemática para ensinar. E na evolução desse saber mais e mais firma-se a identidade do educador matemático, no contraponto ao professor de matemática: o primeiro revela-se no domínio da matemática para ensinar, em sua articulação com a matemática a ensinar; o segundo, não reconhece a matemática para ensinar, advoga a existência de uma única matemática para a formação dos futuros docentes.

\section{Referências}

BORER, V. L. Les savoirs: un enjeu crucial de l'institutionnalisation des formations à l'enseignement. In: Rita Hofstetter et al. Savoirs en (trans)formation - Au coeur des professions de l'enseignement et de la formation. Bruxelles: Éditions De Boeck Université, 2009. p. 41-58.

CIEM. Rapport préliminaire sur l'organisation de la Commission et le plan général de ses travaux. L’Enseignement mathématique. Paris, v. 10, 1908.

FONTES, S. O futurismo e a matemática. Rio de Janeiro: Jornal do Commercio, 6 abril de 1930.

HOFSTETTER, R.; SCHNEUWLY, B. Introduction. In: HOFSTETTER, R. et al. Savoirs en (trans)formation - Au coeur des professions de l'enseignement et de la formation. Bruxelles: Éditions De Boeck Université, 2009. p. 7-40. 
PATRAS, F. La pensée mathématique contemporaine. Paris: Press Universitaires de France, 2001.

MOREIRA, P. C.; DAVID, M. M. M. S. A formação matemática do professor: licenciatura e prática docente. Belo Horizonte: Autêntica, 2005.

ROXO, E. Curso de Mathematica Elementar. v. 1. Rio de Janeiro: Livraria Francisco Alves, 1929.

SANTOS, J. R. V.; LINS, R. C. Uma discussão a respeito da(s) matemática(s) na formação inicial de professores de matemática. Educação Matemática Pesquisa, PUC-SP, V. 18, n. 1, p. 351-372, 2016. Acesso: <http://revistas.pucsp.br/index. php/emp/article/viewFile/20429/pdf>.

VALENTE, W. R. Euclides Roxo e o movimento internacional da matemática escolar. IN: VALENTE, W. R. (Org.). Euclides Roxo e a modernização do ensino de matemática no Brasil. Brasília: Editora da UnB, 2004.

Recebido: 09/07/2016

Received: 07/09/2016

Aprovado: 18/08/2016

Approved: 08/18/2016 